\title{
Informed Principal Model and Contract in Supply Chain with Demand Disruption Asymmetric Information
}

\author{
Huan Zhang and Jianli Jiang \\ Department of Economic Management, North China Electric Power University, Baoding, Hebei 071100, China \\ Correspondence should be addressed to Huan Zhang; hd0086@126.com
}

Received 24 March 2016; Accepted 19 May 2016

Academic Editor: Mónica A. López-Campos

Copyright ( $\odot 2016$ H. Zhang and J. Jiang. This is an open access article distributed under the Creative Commons Attribution License, which permits unrestricted use, distribution, and reproduction in any medium, provided the original work is properly cited.

\begin{abstract}
Because of the frequency and disastrous influence, the supply chain disruption has caused extensive concern both in the industry and in the academia. In a supply chain with one manufacturer and one retailer, the demand of the retailer is uncertain and meanwhile may suffer disruption with a probability. Taking the demand disruption probability as the retailer's asymmetric information, an informed principal model with the retailer as the principal is explored to make the contract. The retailer can show its information to the manufacturer through the contract. It is found out that the high-risk retailer intends to pretend to be the low-risk one. So the separating contract is given through the low-information-intensity allocation, in which the order quantity and the transferring payment for the low-risk retailer distort upwards, but those of high-risk retailer do not distort. In order to reduce the signaling cost which the low-risk retailer pays, the interim efficient model is introduced, which ends up with the order quantity and transferring payment distorting upwards again but less than before. In the numerical examples, with two different mutation probabilities, the informed principal contracts show the application of the informed principal model in the supply chain with demand disruption.
\end{abstract}

\section{Introduction}

Supply chain risk management is becoming an increasingly important area. In the past several years, there has been a shift of focus from creating efficient supply chains to reliable and efficient supply chains. This shift is due to the largescale negative impacts of supply chain disruptions in global supply chain networks. For example, in 2013, the "horse meat" incident in Europe led to a plunge in demand of beef products [1]. And the 2015 terrorist attack in Paris depressed the tourism in whole Europe and reduced the demand of aircraft industry. Walmart, Home, and some other large companies have set up specialized disruption management department to deal with disruptions in supply chain [2]. Because of the frequency and disastrous influence, the demand disruption in supply chain has caused extensive concern both in the industry and in the academia.

Snyder et al. figure out that contract designing is one of the most important strategic measures in supply chain disruption management [3]. There is an abundant amount of research available on the topic of contract in supply chain with demand disruption [4-7]. Most research considers the demand disruption as symmetric information [8-11]. The demand disruption may be influenced by the nature, politics, economics, society, or even the finance, management, technology, human, and so on; so there is a different probability or damage degree to suffer disruption by different companies [3]. Through the operation, the company in supply chain knows the environment and its interior, so it can know more about the disruption compared to the others [12]. Hendricks et al. find out that the managers choose not to report or understate the disruption which has a negative effect on the finance or stock price $[13,14]$. Bunkley reports that the motor components suppliers hide some important disruption information after the Tohoku earthquake, which results in the second half to the American motor industry [15]. So the disruption information is not symmetric between the anticipants of supply chain. The experiment in Sarkar and Kumar confirms that the asymmetry of demand disruption information reduces the efficiency of supply chain [16]. Asymmetric information leads to low supply chain efficiency [17], so lots of research focuses on coordinating the supply 
chains with asymmetric information [18-23]. So it is important to consider the asymmetric disruption information when we design the supply chain contract [24]. But very few researchers pay attention to the asymmetric disruption information. Gümüş et al. consider the supply disruption probability as the supplier's asymmetric information and give the optimal incentive contract $[12,25]$. Lei et al. derive the optimal linear contract and wholesale contract with the impact of asymmetric demand disruption and cost disruption information [24]. Huang and Yang set up the principal agent model and make the incentive contract, considering the demand disruption information asymmetric [26].

In this paper, we consider the demand disruption probability as the retailer's private information in order to investigate the contract between the supplier and the retailer. In the available research about asymmetric information in supply chain, researchers always try to reveal the retailer's private information by a menu of incentive contracts [27-29] or sharing the information $[30,31]$ to improve the interests. In all of the researches, the principal agent theory is explored and the party with no private information is seen as the principal. As Myerson et al. point out, there are limitations of the assumption of the principal with no private information. In many contracts, for example, the sales contract, employment contract, and regulation contract, it is common for the party with private information to be the principal who makes the contract [32-35]. So we consider the following situation: in a supply chain with one manufacturer and one retailer, the retailer may suffer demand disruption with a certain probability. And the retailer with the asymmetric demand disruption probability information makes the supply chain contract to express its own information to the manufacturer. Then the retailer can differ from the other retailer by providing this contract.

Differing from those of prior studies, the major innovations of the research are as follows.

(1) We consider demand uncertainty and demand disruption simultaneously, and the demand disruption probability is considered as the retailer's asymmetric information. Demand uncertainty is commonly considered in the supply chain research, and demand disruption happens on occasion. Both the demand uncertainty and demand disruption impact the supply chain contract making. And demand disruption is totally different from demand uncertainty, so demand uncertainty and demand disruption should be considered together in the supply chain contract [3]. Lots of research pays more attention to the coordination contract in supply chain with demand disruption, but most is studied without asymmetric disruption information $[24,26]$.

(2) The informed principal model is explored for the separating contract in the supply chain with asymmetric demand disruption information. In the research $[24,26]$, the supplier as the principal makes the contract to encourage the retailer to show its own demand disruption information. But we use the informed principal model and consider the retailer with the demand disruption information to be the principal. The retailer can deliver its own information to the manufacturer and can be distinguished from the others from the separating contract [35-38].
The reminder of this paper is organized as follows. In Section 2, the concerned problem is defined, and the assumptions and notations are given. The full information model and optimal contract are given in Section 3. Section 4 goes into the informed principal model. In Section 5, the interim efficient allocation is given to reduce the signaling cost in the informed principal model. Numerical examples are presented in Section 6, and sensitivity analysis is carried out with respect to some key model parameters. The paper concludes with Section 7, in which we provide a summary of the paper and future research directions.

\section{Model Description}

We consider a supply chain consisting of one risk neutral manufacturer and one risk neutral retailer. When the selling season comes, the retailer purchases a kind of product from the manufacturer and then sells it into market. The market of the retailer may suffer disruption. And different retailers have different probability to experience the disruption. Supposing the disruption probability as the retailer's private information, the informed principal model is set up to design the contracts, with which the retailer can demonstrate its true information to the manufacturer.

2.1. Assumptions. The informed principal model of the supply chain with demand disruption meets the following assumptions. To make the presentation clear, we also list the relevant variables or notations (see Variable/Notations section).

Assumption 1. Before the selling season comes, the retailer makes order $q$ from the manufacturer, and the manufacturer supplies the right quantity $q$ to the retailer, with the unit manufacturing $\cos t c$. Then the retailer pays $t$ as the transferring payment. And when the selling season comes, the retailer sells the products to the demand market with the price $p$.

Assumption 2. The retailer faces an unstable market, which means the demand in this market may suffer disruption. Without disruption, the demand $y$ belongs to $[0, A]$ with the distribution function $F(y)$ and the density function $f(y)$. With the demand disruption, the retailer's demand $x$ belongs to $[0, D]$, with the distribution function $G(x)$ and density function $g(x)$. The demand belongs to the same distribution style whenever with disruption or without disruption, for example, uniform distribution and normal distribution, and the market scale without disruption is larger than that with disruption, $A>D$. And $E(x)=A / 2, E(y)=D / 2, \operatorname{Var}(x)>$ $\operatorname{Var}(y)$. So for the same demand $x^{0}=y^{0}$, the distribution function meets $G\left(x^{0}\right) \geq F\left(y^{0}\right)$. It means when the demand disruption happens, the demand, which is less than the given demand $x^{0}$ or $y^{0}$, happens in a larger probability than that of the demand without disruption.

Assumption 3. There are two kinds of retailers, the low-risk one with demand disruption probability $\alpha_{1}$ and the high-risk one with demand disruption probability $\alpha_{2}$, while $\alpha_{1}<\alpha_{2}$. The demand disruption probability is the retailer's individual information. The manufacturer only knows there is a low-risk 


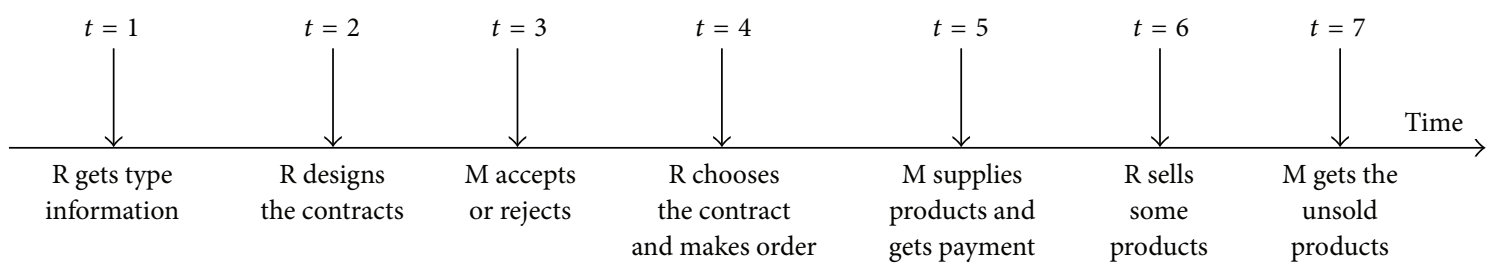

FIGURE 1: Informed principal game sequence in supply chain with demand disruption R means the retailer; $M$ means the manufacturer.

retailer with the probability $\lambda$ and a high-risk retailer with the probability $1-\lambda$. Both the high-risk retailer and the low-risk retailer are risk neutral.

Assumption 4. The retailer as the informed principal designs the transferring contracts, by which the retailer can demonstrate its true information to the manufacturer. The transferring contract for low-risk retailer is $\left\{t_{1}, q_{1}\right\}$, while for highrisk one it is $\left\{t_{2}, q_{2}\right\}$.

Assumption 5. Every unsold product has the salvage value $s(s<c)$. And the manufacturer has the salvage value of the unsold products. For example, the unsold products can be reused for the manufacturer, but the retailer has to pay for disposing them. The manufacturer can get the unsold products free from the retailer and reuse them. In this case, the manufacturer has the salvage value of the unsold products.

$S\left(\alpha_{i}, q_{i}\right)(i=1,2)$ denote the low-risk retailer's and highrisk retailer's expected sales:

$$
\begin{aligned}
S\left(\alpha_{i}, q_{i}\right)= & \alpha_{i}\left(q_{i}-\int_{0}^{q_{i}} G(x) d x\right) \\
& +\left(1-\alpha_{i}\right)\left(q_{i}-\int_{0}^{q_{i}} F(y) d y\right) .
\end{aligned}
$$

$I\left(\alpha_{i}, q_{i}\right)(i=1,2)$ denote the low-risk retailer's and highrisk retailer's expected unsold quantity:

$$
I\left(\alpha_{i}, q_{i}\right)=\alpha_{i} \int_{0}^{q_{i}} G(x) d x+\left(1-\alpha_{i}\right) \int_{0}^{q_{i}} F(y) d y .
$$

$U_{i}(i=1,2)$ denote the low-risk retailer's and high-risk retailer's utility:

$$
U_{i}=p S\left(\alpha_{i}, q_{i}\right)-t_{i}
$$

$V_{i}(i=1,2)$ denote the manufacturer's utility when it cooperates with the low-risk retailer or high-risk retailer:

$$
V_{i}=t_{i}-c q_{i}+s I\left(\alpha_{i}, q_{i}\right)
$$

2.2. Game Sequence. When the retailer faces the demand disruption, the sequence of the informed principal game between the manufacturer and the retailer is shown as follows (Figure 1):

(1) The retailer knows its type information $\alpha_{i}$.

(2) The retailer as the informed principal designs the transferring contract package $\left\{\left(t_{1}, q_{1}\right),\left(t_{2}, q_{2}\right)\right\}$.
(3) The manufacturer accepts or rejects the contract.

(4) Before the selling season, the retailer chooses the transferring contract according to its type and makes the order $q_{i}$.

(5) The manufacturer supplies products, and the retailer pays $t_{i}$ for them.

(6) In the selling season, the demand disruption occurs in a certain probability, and the retailer sells some products.

(7) After the selling season, the manufacturer gets the unsold products.

\section{Full Information Model}

3.1. Modeling. When the demand disruption probability is public information, the different retailers should provide the single selected contracts $\left(t_{1}, q_{1}\right)$ or $\left(t_{2}, q_{2}\right)$. We can get this pair of single selected contracts by solving the following programs $\left\{P_{F}^{1}\right\}$ and $\left\{P_{F}^{2}\right\}$ :

$$
\begin{aligned}
& P_{F}^{1} \text { : } \\
& \max _{\left\{t_{1}, q_{1}\right\}} \quad U_{1}=p S\left(\alpha_{1}, q_{1}\right)-t_{1} \\
& \text { s.t. } \quad V_{1}=t_{1}-c q_{1}+s I\left(\alpha_{1}, q_{1}\right) \geq 0 \text {; } \\
& \max _{\left\{t_{2}, q_{2}\right\}} \quad U_{2}=p S\left(\alpha_{2}, q_{2}\right)-t_{2} \\
& \text { s.t. } \quad V_{2}=t_{2}-c q_{2}+s I\left(\alpha_{2}, q_{2}\right) \geq 0 \text {. }
\end{aligned}
$$

The targets of these programs are the retailers' revenue, which are the principal. As in the full information situation, each participant knows the true information, so there is no incentive compatible constraint. Whatever, the manufacturer should get no less than the retrained revenue. The incentive rationality constraint of the manufacturer facing different retailers is useful here (see (6) and (8)).

3.2. Results. By solving programs $\left\{P_{F}^{1}\right\}$ and $\left\{P_{F}^{2}\right\}$, there comes Proposition 6 (Proof of Proposition 6 is given in Appendix A).

Proposition 6. (1) Under full information, the optimal contract in supply chain with demand disruption satisfies that both the optimal order and optimal transferring payment for 


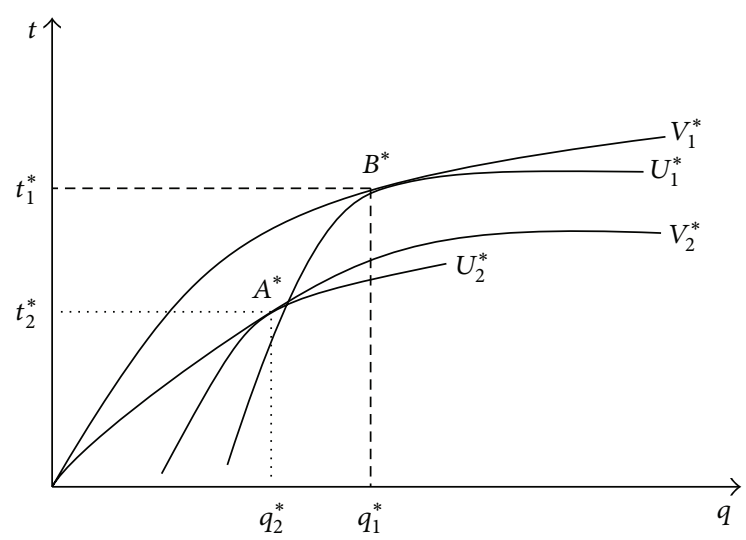

FIGURE 2: Supply chain contract under full information.

low-risk retailer are higher than those for high-risk retailer, as $q_{1}^{*}>q_{2}^{*}, t_{1}^{*}>t_{2}^{*}$.

(2) Under full information, the utility of the low-risk retailer is larger than that of high-risk retailer, as $U_{1}^{*}>U_{2}^{*}$, and the utility of the manufacturer cooperating with low-risk retailer and with high-risk retailer is equal to the retrained revenue, as $V_{1}^{*}=V_{2}^{*}=0$.

From Proposition 6, it is obvious that under full information the low-risk retailer should make more orders than the high-risk retailer $\left(q_{1}^{*}>q_{2}^{*}\right)$ and meanwhile pay more $\left(t_{1}^{*}>t_{2}^{*}\right)$. Let us show the optimal contract in Figure 2, using the retailer and the manufacturer indifferent utility curve. For the low-risk retailer, the optimal contract is shown at point $B^{*}$. And for the high-risk retailer, the optimal contract is shown at point $A^{*}$. The retailer's utility grows more when its indifferent curve goes into southeast. So when the lowrisk retailer pretends to be high-risk one, using allocation $A^{*}$, which is to say that the low-risk retailer's indifferent utility curve goes northwest, its utility decreases. But if the highrisk retailer pretends to be low-risk one, using allocation $B^{*}$, its utility increases. So as the self-interested participant, the high-risk retailer tends to pretend to be low-risk one. Then we can get Proposition 7.

Proposition 7. Considering the demand disruption probability as the retailer's individual information, the optimal allocation for the low-risk retailer is not separating equilibrium allocation.

\section{Informed Principal Model}

In order to show its true type information, the retailer can use the informed principal model to offer an option contract [32]. The term "option contract $\left\{\left(t_{1}, q_{1}\right),\left(t_{2}, q_{2}\right)\right\}$ " comes from the fact that if the manufacturer accepts the contract, the retailer must then exercise its built-in option and choose between $\left(t_{1}, q_{1}\right)$ and $\left(t_{2}, q_{2}\right)$. The retailer will choose the term which is fit to its own type by probability $100 \%$, as $p\left\{\alpha_{1} \mid\left(t_{1}, q_{1}\right)\right\}=$ $p\left\{\alpha_{2} \mid\left(t_{2}, q_{2}\right)\right\}=1$. And the retailer will choose the term which is not fit to its own probability by probability 0 , as $p\left\{\alpha_{1} \mid\left(t_{2}, q_{2}\right)\right\}=p\left\{\alpha_{2} \mid\left(t_{1}, q_{1}\right)\right\}=0[33,34]$. Then the informed principal model of the supply chain with demand disruption is built up for the Perfect Bayesian Equilibrium.

4.1. Modeling. Firstly, the incentive compatible constraint is given. The option contract is incentive compatible, if the lowrisk retailer prefers the contract item $\left(t_{1}, q_{1}\right)$ and the highrisk retailer prefers the contract item $\left(t_{2}, q_{2}\right)$. So the incentive compatible constraint should keep the low-risk retailer's utility no less than when it pretends to be a high-risk one:

$$
p S\left(\alpha_{1}, q_{1}\right)-t_{1} \geq p S\left(\alpha_{1}, q_{2}\right)-t_{2}
$$

And the high-risk retailer's utility is no less than when it pretends to be a low-risk one:

$$
p S\left(\alpha_{2}, q_{2}\right)-t_{2} \geq p S\left(\alpha_{2}, q_{1}\right)-t_{1} .
$$

Secondly, the incentive rationality constraint is given. The retailer with the individual information is the principal, and the manufacturer without individual information is the agent. So the agent's incentive rationality is the same as that (as in (6) and (8)) in full information situation.

Thirdly, the target function is given. The target of the informed principal model is also to maximize the utility of the principal, or to say the retailer.

So the programs under informed principal of supply chain with demand disruption are $\left\{P_{I}^{1}\right\}$ and $\left\{P_{I}^{2}\right\}$. Consider the following:

$$
\begin{array}{lll}
P_{I}^{1}: & & \\
& \max _{\left\{t_{1}, q_{1}\right\}} & U_{1}=p S\left(\alpha_{1}, q_{1}\right)-t_{1} \\
& \text { s.t. } & (6)(8)(9)(10) ; \\
P_{I}^{2}: & & \\
& \max _{\left\{t_{2}, q_{2}\right\}} & U_{2}=p S\left(\alpha_{2}, q_{2}\right)-t_{2} \\
& \text { s.t. } & (6)(8)(9)(10) .
\end{array}
$$

Definition 8. Utility $U_{1}\left(t_{1}^{0}, q_{1}^{0}\right) / U_{2}\left(t_{2}^{0}, q_{2}^{0}\right)$ for low-risk/highrisk retailer is the low-information-intensity optimum for that type if $\left(t_{1}^{0}, q_{1}^{0}\right) /\left(t_{2}^{0}, q_{2}^{0}\right)$ maximizes low-risk retailer's utility in the set of incentive compatible constraint and incentive rationality constraint. They are (part of) the solution to the programs $\left\{P_{I}^{1}\right\}$ and $\left\{P_{I}^{2}\right\}$.

For solving the informed principal model, the assumption of weak monotonic profit is listed as follows.

Assumption 9. It is weak monotonic profit when the manufacturer makes a nonnegative profit if the contractual terms are those of low-risk retailer under symmetric information and the retailer is a high-risk one: $V_{1}\left(t_{2}^{*}, q_{2}^{*}\right) \geq 0$.

From Figure 2, if the contractual term for the low-risk retailer changes from $B^{*}$ to $A^{*}$, the curve $V_{1}^{*}$ will go southeast, and the manufacturer's profit increases. So the manufacturer's profit is no less than 0 , and Assumption 9 is satisfied. 
Definition 10. The separating allocation is the allocation $\left(t_{1}^{s}\right.$, $q_{1}^{s}$ ) for the low-risk retailer and the symmetric information contractual terms $\left(t_{2}^{*}, q_{2}^{*}\right)$ are for the high-risk retailer, where $\left(t_{1}^{s}, q_{1}^{s}\right)$ maximizes the low-risk retailer's utility subject to the manufacturer's breaking even for the low-risk retailer and to the high-risk retailer not preferring $\left(t_{1}^{s}, q_{1}^{s}\right)$ to $\left(t_{2}^{*}, q_{2}^{*}\right)$. The program is listed as $\left\{P_{s}^{1}\right\}$ :

$$
\begin{array}{ll}
P_{s}^{1}: & \\
\max _{\left\{t_{1}, q_{1}\right\}} & U_{1}=p S\left(\alpha_{1}, q_{1}\right)-t_{1} \\
\text { s.t. } & (6) \\
& p S\left(\alpha_{2}, q_{2}^{*}\right)-t_{2}^{*} \geq p S\left(\alpha_{2}, q_{1}\right)-t_{1} .
\end{array}
$$

\subsection{Results}

Proposition 11. Under the weak monotonic-profit assumption, the separating allocation is the low-information-intensity optimum.

Proof. (1) The high-risk retailer can get its asymmetric information utility even under asymmetric information. Comparing programs $\left\{P_{F}^{2}\right\}$ and $\left\{P_{I}^{2}\right\}$, it can be found that these two programs have the same target function, but $\left\{P_{F}^{2}\right\}$ has less constraints, so $U\left(t_{2}^{*}, q_{2}^{*}\right) \geq U\left(t_{2}^{0}, q_{2}^{0}\right)$. According to Assumption 9, the manufacturer at least breaks even regardless of the retailer's type. Hence, $\left(t_{2}^{*}, q_{2}^{*}\right)$ is the separating allocation item for high-risk retailer.

(2) Because $U\left(t_{2}^{*}, q_{2}^{*}\right) \geq U\left(t_{2}^{0}, q_{2}^{0}\right)$, constraint (14) is more restricted than (10). For the low-risk retailer, the programs $\left\{P_{I}^{1}\right\}$ and $\left\{P_{1}^{s}\right\}$ have the same target functions, but there are more constraints in the former program, so $U\left(t_{1}^{s}, q_{1}^{s}\right) \geq$ $U\left(t_{1}^{0}, q_{1}^{0}\right)$ is satisfied. And the low-risk retailer at least can get $U\left(t_{1}^{s}, q_{1}^{s}\right)$ from the option contract. From the incentive compatibility constraint (14) which can be rewritten as $U_{2}\left(t_{2}^{*}, q_{2}^{*}\right) \geq U_{2}\left(t_{1}^{s}, q_{1}^{s}\right)$, it has been guaranteed that the highrisk retailer will not choose $\left\{t_{1}^{s}, q_{1}^{s}\right\}$. From the program $\left\{P_{1}^{s}\right\}$, the low-risk retailer can get more utility when the contractual item is $\left\{t_{1}^{s}, q_{1}^{s}\right\}$ than that of $\left\{t_{2}^{*}, q_{2}^{*}\right\}$. So we can get $\left\{t_{1}^{0}, q_{1}^{0}\right\}=$ $\left\{t_{1}^{s}, q_{1}^{s}\right\}$. $\operatorname{dix} B)$.

Then we can get Proposition 12 (see details in Appen-

Proposition 12. As for the option contract by informed retailer in supply chain with demand disruption, the low-informationintensity allocation satisfies the following:

(1) Comparing to the full information situation, the lowinformation-intensity allocation for high-risk retailer and its utility does not distort, as $t_{2}^{0}=t_{2}^{*}, q_{2}^{0}=q_{2}^{*}$, $U_{2}\left(t_{2}^{0}, q_{2}^{0}\right)=U_{2}^{*}$.

(2) Comparing to the full information situation, the lowinformation-intensity allocation for low-risk retailer has upward distortion $t_{1}^{0}>t_{1}^{*}, q_{1}^{0}>q_{1}^{*}$, while its utility has downward distortion $U_{1}\left(t_{1}^{0}, q_{1}^{0}\right)<U_{1}^{*}$.
(3) The order quantities in the low-information-intensity allocation for the retailers in different types satisfy

$$
\begin{aligned}
p S & \left(\alpha_{2}, q_{1}^{0}\right)-c q_{1}^{0}+s I\left(\alpha_{1}, q_{1}^{0}\right) \\
& =p S\left(\alpha_{2}, q_{2}^{*}\right)-c q_{2}^{*}+s I\left(\alpha_{2}, q_{2}^{*}\right) .
\end{aligned}
$$

In the informed principal model, in order to prevent the high-risk retailer from pretending to be a low-risk one, the low-information-intensity allocation items for the low-risk retailer distort. The low-risk retailer should order more than the optimal order and pay more than the optimal transferring payment. But the utility of the low-risk retailer is less than the optimal one, which means the low-risk retailer pays some rent to separate from the high-risk retailer. So the rent is called signaling cost.

\section{Interim Efficient Allocation}

The retailer can deliver its own type information to the manufacturer by low-information-intensity allocation in the informed principal model. But the low-risk retailer's order and transferring payment distort relative to the full information situation, and it has to pay the signaling cost. The signaling cost is the part utility which the low-risk retailer gets less than the optimal. So maybe we can decrease the signaling cost by increasing the high-risk retailer's utility and meanwhile increasing the low-risk retailer's utility. So in this part, we try to find a separating equilibrium with less signaling cost $[32-34,38]$, by the interim efficient model.

Let us consider the interim efficient model which can decrease the signaling cost by giving the high-risk retailer more than optimal utility. Let $\widehat{R}$ be the utility which the highrisk retailer gets more than the optimal one. And let $L(\widehat{R})$ be the minimal loss of the manufacturer when it cooperates with the high-risk retailer. $L(\widehat{R})$ can be gotten by the program $\left\{P_{m}^{2}\right\}$ :

$$
\begin{aligned}
& P_{m}^{2}: \\
& -L(\widehat{R})=\max _{\left\{t_{2}, q_{2}\right\}} \quad\left\{t_{2}-c q_{2}+s I\left(\alpha_{2}, q_{2}\right)\right\} \\
& \text { s.t. } \quad p S\left(\alpha_{2}, q_{2}\right)-t_{2} \\
& \\
& \geq p S\left(\alpha_{2}, q_{2}^{*}\right)-t_{2}^{*}+\widehat{R} .
\end{aligned}
$$

It is easy to find out that when constraint (17) is binding, $q_{2}=q_{2}^{*}$ and $L(\widehat{R})=\widehat{R}$.

Definition 13. Utility $U_{1}\left(t_{1}^{m}, q_{1}^{m}\right) / U_{2}\left(t_{2}^{m}, q_{2}^{m}\right)$ for low-risk/ high-risk retailer is the interim efficient optimum for that type if $\left(t_{1}^{m}, q_{1}^{m}\right) /\left(t_{2}^{m}, q_{2}^{m}\right)$ maximizes low-risk retailer's utility in the set of incentive compatible constraint and the manufacturer's expected profit. And the contract $\left\{\left(t_{1}^{m}, q_{1}^{m}\right),\left(t_{2}^{m}, q_{2}^{m}\right)\right\}$ is the interim efficient allocation. They are (part of) the solution to the programs $\left\{P_{m}^{1}\right\}$ and $\left\{P_{m}^{2}\right\}$ : 
TABLE 1: Full information contract versus low-information-intensity allocation.

\begin{tabular}{|c|c|c|c|c|c|}
\hline $\begin{array}{l}\text { Type of } \\
\text { retailer }\end{array}$ & Full information & $\begin{array}{c}\text { Low } \\
\text { information } \\
\text { intensity }\end{array}$ & $\begin{array}{l}\text { Type of } \\
\text { retailer }\end{array}$ & Full information & $\begin{array}{c}\text { Low } \\
\text { information } \\
\text { intensity }\end{array}$ \\
\hline \multirow{3}{*}{$\alpha_{1}=0.2$} & $q_{1}^{*}=10.01$ & $q_{1}^{0}=10.14$ & \multirow{3}{*}{$\alpha_{1}=0.3$} & $q_{1}^{*}=9.90$ & $q_{1}^{0}=10.02$ \\
\hline & $t_{1}^{*}=18.62$ & $t_{1}^{0}=18.81$ & & $t_{1}^{*}=18.40$ & $t_{1}^{0}=18.24$ \\
\hline & $U_{1}^{*}=53.40$ & $U_{1}^{0}=53.38$ & & $U_{1}^{*}=52.78$ & $U_{1}^{0}=51.92$ \\
\hline \multirow{3}{*}{$\alpha_{2}=0.4$} & $q_{2}^{*}=9.78$ & $q_{1}^{0}=9.78$ & \multirow{3}{*}{$\alpha_{2}=0.5$} & $q_{2}^{*}=9.67$ & $q_{2}^{0}=9.67$ \\
\hline & $t_{2}^{*}=18.19$ & $t_{2}^{0}=18.19$ & & $t_{2}^{*}=17.99$ & $t_{2}^{0}=17.99$ \\
\hline & $U_{2}^{*}=52.17$ & $U_{2}^{0}=52.17$ & & $U_{2}^{*}=51.59$ & $U_{2}^{0}=51.59$ \\
\hline
\end{tabular}

$$
\begin{aligned}
\max _{m}^{1}: & \\
\max _{\left\{t_{1}, q_{1}, \widehat{R}\right\}} & U_{1}=p S\left(\alpha_{1}, q_{1}\right)-t_{1} \\
\text { s.t. } & \lambda\left(t_{1}^{m}-c q_{1}^{m}+s I\left(\alpha_{1}, q_{1}^{m}\right)\right)-(1-\lambda) \widehat{R} \geq 0 \\
& p S\left(\alpha_{2}, q_{2}^{*}\right)-t_{2}^{*}+\widehat{R} \geq p S\left(\alpha_{2}, q_{1}^{m}\right)-t_{1}^{m} .
\end{aligned}
$$

The high-risk retailer can get the rent $\widehat{R}$ above the optimum, so the manufacturer will lose some utility. Then the incentive rational constraint (see (19)) for the manufacturer is the expected profit rather than the individual profit. Equation (20) is the incentive compatible constraint for the high-risk retailer.

From programs $\left\{P_{m}^{1}\right\}$ and $\left\{P_{m}^{2}\right\}$, we can get Propositions 14 and 15 (see Proof in Appendix C).

Proposition 14. The interim efficient allocation by informed principal for the supply chain with demand disruption satisfies the following:

(1) Comparing to the full information situation, the order quantity for the high-risk retailer does not distort, $q_{2}^{m}=$ $q_{2}^{*}$.

(2) Comparing to the full information situation, the order quantity for the low-risk retailer satisfies (21) and distorts upwards, $q_{1}^{m}>q_{1}^{*}$. Consider

$$
\begin{aligned}
& s I^{\prime}\left(\alpha_{1}, q_{1}^{m}\right)+p S^{\prime}\left(\alpha_{1}, q_{1}^{m}\right)-c \\
& \quad=\frac{1-\lambda}{\lambda}\left[p S^{\prime}\left(\alpha_{2}, q_{1}^{m}\right)-p S^{\prime}\left(\alpha_{1}, q_{1}^{m}\right)\right] .
\end{aligned}
$$

(3) The transferring payment for the low-risk retailer meets (22), and the transferring payment for the high-risk retailer meets (23):

$$
\begin{aligned}
t_{1}^{m} & =(1-\lambda) \\
& \cdot\left[p S\left(\alpha_{2}, q_{1}^{m}\right)-p S\left(\alpha_{2}, q_{2}^{*}\right)+c q_{2}^{*}-s I\left(\alpha_{2}, q_{2}^{*}\right)\right] \\
& +\lambda\left[c q_{1}^{m}-s I\left(\alpha_{1}, q_{1}^{m}\right)\right] \\
t_{2}^{m} & =(1-\lambda)\left[c q_{2}^{*}-s I\left(\alpha_{2}, q_{2}^{*}\right)\right]+\lambda p S\left(\alpha_{2}, q_{2}^{*}\right) \\
& +\lambda\left[c q_{1}^{m}-s I\left(\alpha_{1}, q_{1}^{m}\right)-p S\left(\alpha_{2}, q_{1}^{m}\right)\right] .
\end{aligned}
$$

Proposition 15. There is a threshold $\lambda^{0}=\left(p S^{\prime}\left(\alpha_{2}, q_{1}^{0}\right)-\right.$ $\left.p S^{\prime}\left(\alpha_{1}, q_{1}^{0}\right)\right) /\left(s I^{\prime}\left(\alpha_{1}, q_{1}^{0}\right)+p S^{\prime}\left(\alpha_{2}, q_{1}^{0}\right)-c\right)$ for the low-risk retailer probability. If and only if the probability of low-risk retailer is no more than the threshold $\lambda \leq \lambda^{0}$, the low-information-intensity allocation is also interim efficient and is the unique Perfect Bayesian Equilibrium. If the probability of low-risk retailer is more than the threshold $\lambda>\lambda^{0}$, the low-information-intensity allocation is not the unique Perfect Bayesian Equilibrium.

If and only if the probability of low-risk retailer is small enough $\left(\lambda \leq \lambda^{0}\right)$, the low-information-intensity allocation is the unique Perfect Bayesian Equilibrium. And the retailer can deliver its own type information by the separating contract. But if the low-risk retailer is more than that $\left(\lambda>\lambda^{0}\right)$, the lowinformation-intensity allocation is not the unique Perfect Bayesian Equilibrium, and the interim efficient allocation can improve the distortion situation to a certain degree. So for the supply chain with demand disruption, the optimal allocation cannot be reached if the informed principal provides a separating contract.

\section{Numerical Example}

This section gives some numerical examples to inspect the supply chain contract with demand disruption by informed principal. We let the sales price $p=10$, the unit manufacturing cost is $c=2$, and the salvage product value is $s=0.5$. The demand distribution function before disruption is $F(y)=y^{2} / 125$, and the demand distribution function after disruption is $G(x)=x^{2} / 100$.

6.1. Main Results. From the example listed above, the full information contracts and low-information-intensity allocation are given in Table 1.

Table 1 shows that, for the full information contract, the order quantity for low-risk retailer is larger than that for the high-risk retailer $q_{1}^{*}>q_{2}^{*}$, and also the transferring payment $t_{1}^{*}>t_{2}^{*}$, which is performed in Proposition 6. In the informed principal model, the order quantity for the low-risk retailer distorts in order to show its type (when $\alpha_{1}=0.2$ versus $\alpha_{2}=$ $0.4, q_{1}^{*}=10.01<q_{1}^{\text {sb }}=10.14$, and when $\alpha_{1}=0.3$ versus $\left.\alpha_{2}=0.5, q_{1}^{*}=9.90<q_{1}^{0}=10.02\right)$. Meanwhile, we notice that the utility obtained by the low-risk retailer in the informed 


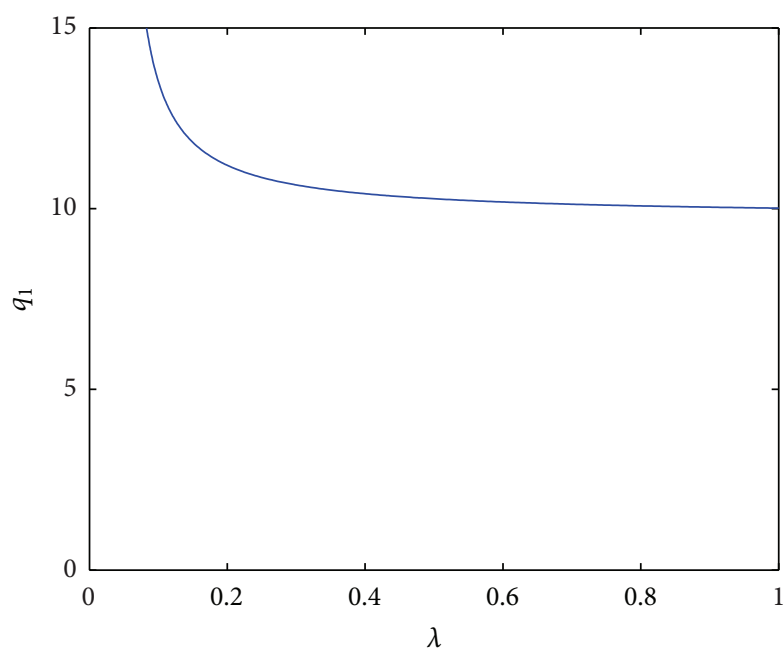

FIGURE 3: The order quantity in interim efficient allocation for lowrisk retailer changes by its probability.

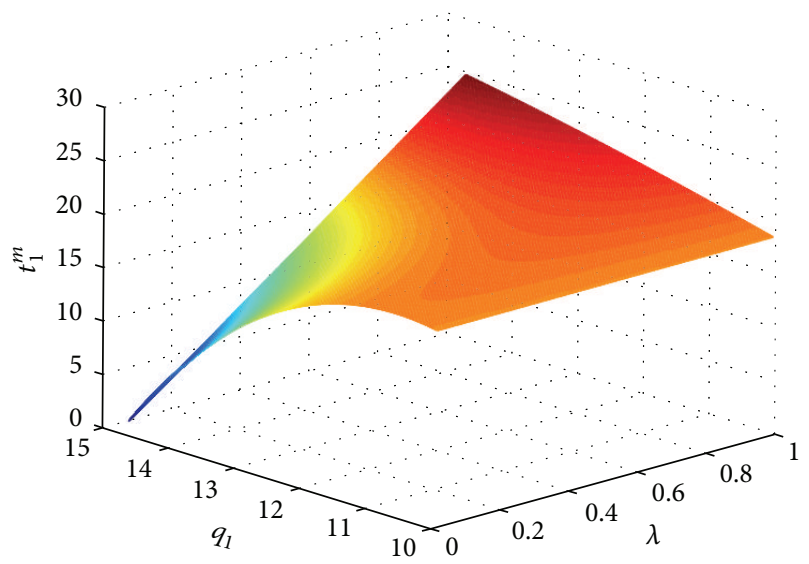

FIGURE 4: The transferring payment in interim efficient allocation for low-risk retailer changes by the order quantity and its probability.

principal model is lower than that in full information model (when $\alpha_{1}=0.2$ versus $\alpha_{2}=0.4, U_{1}^{*}=53.40>U_{1}^{0}=53.38$, and when $\alpha_{1}=0.3$ versus $\alpha_{2}=0.5, t_{1}^{*}=18.40>t_{1}^{0}=18.24$ ). This implies that it costs the low-risk retailer something to certify its type. These results are the same with Proposition 12 .

Considering the situation of $\alpha_{1}=0.2$ versus $\alpha_{2}=0.4$, we obtain $\lambda^{0}=0.19$. The order quantity for the low-risk retailer $q_{1}^{m}$ changes with the proportion it has $\lambda$ in interim efficient allocation. As Figure 3 shows, if and only if $\lambda$ varies within certain area $\left(\lambda \leq \lambda^{0}\right)$, we obtain $q_{1}^{m}>q_{1}^{*}$, as in the results in Proposition 14.

The transferring payment in the interim efficient allocation is depicted in Figure 4 (for the low-risk retailer) and Figure 5 (for the high-risk retailer). The transferring payments are changing by the order quantity for the lowrisk retailer in the interim efficient allocation and the lowrisk retailer's probability. From Figure 4, when the low-risk retailer's probability $\lambda$ is less enough and the order quantity for the low-risk retailer $q_{1}^{m}$ is high enough, the transferring

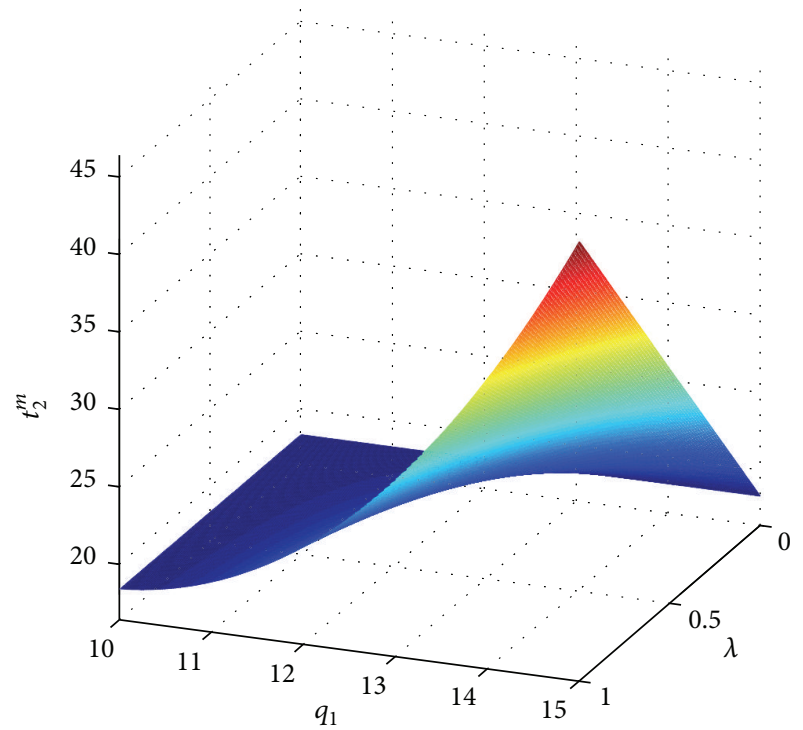

FIGURE 5: The transferring payment in interim efficient allocation for high-risk retailer changes by the low-risk retailer's order quantity and probability.

payment $t_{1}^{m}$ increases by the low-risk retailer's probability $\lambda$ but decreases by the order quantity for the low-risk retailer $q_{1}^{m}$ (bottom left in Figure 4). But, mostly, the transferring payment $t_{1}^{m}$ increases by the low-risk retailer's probability $\lambda$ but decreases by the order quantity for the low-risk retailer $q_{1}^{m}$ (red and orange part in Figure 4). Normally, the transferring payment should increase by the order quantity, which means "get more pay more." From this view, the low-risk retailer's probability $\lambda$ should not be very small, and the order quantity for the low-risk retailer $q_{1}^{m}$ should not be close to the maximum value 15 .

From Figure 5, it is obviously seen that the transferring payment for high-risk retailer in the interim efficient allocation $t_{2}^{m}$ increases by the order quantity for the low-risk retailer $q_{1}^{m}$ but decreases by the low-risk retailer's probability $\lambda$.

6.2. Sensitivity Analyses. The sensitivity analyses for the lowinformation-intensity allocation versus the unit manufacturing cost $c$ are shown in Table 2. It shows the outcomes when the unit manufacturing cost $c$ changes by $+25 \%$ and $-25 \%$ once at a time and keeping remaining parameters. The order quantities decrease by the unit manufacturing cost, but the influence for the high-risk retailer's order quantity is larger than that for the low-risk retailer $(-0.69 \%$ versus $-3.17 \%$ and $+2.17 \%$ versus $+3.07 \%$ ). The transferring payments increase by the unit manufacturing cost. More interesting, the utilities decrease by the unit manufacturing cost, and the low-risk retailer receives a greater impact $(-9.40 \%$ versus $-9.22 \%$ and $+9.55 \%$ versus $+9.53 \%$ ). So from this point of view, the lowrisk retailer should encourage the manufacturer to reduce the cost more.

Figure 6 shows the sensitivity analyses for the order quantities versus the unit manufacturing cost, in which the order quantities include the order quantity for the low-risk retailer in low-information-intensity allocation $q_{1}^{0}$, the order quantity 
TABLE 2: Sensitivity analyses for low-information-intensity allocation versus the unit manufacturing cost.

\begin{tabular}{|c|c|c|c|c|c|}
\hline \multirow[b]{2}{*}{ Value } & Changes of $c$ & \multicolumn{2}{|c|}{$\begin{array}{l}\text { The low-information allocation for low-risk } \\
\text { retailer }\left(\alpha_{1}=0.2\right)\end{array}$} & \multicolumn{2}{|c|}{$\begin{array}{l}\text { The low-information allocation } \\
\text { for high-risk retailer }\left(\alpha_{2}=0.4\right)\end{array}$} \\
\hline & Change rate & Value & Change rate & Value & Change rate \\
\hline \multirow{3}{*}{$c=2.5$} & & $q_{1}^{0}=10.07$ & $-0.69 \%$ & $q_{2}^{0}=9.47$ & $-3.17 \%$ \\
\hline & $+25 \%$ & $t_{1}^{0}=23.75$ & $+26.26 \%$ & $t_{2}^{0}=22.43$ & $+23.31 \%$ \\
\hline & & $U_{1}^{0}=48.36$ & $-9.40 \%$ & $U_{2}^{0}=47.36$ & $-9.22 \%$ \\
\hline \multirow{3}{*}{$c=2$} & & $q_{1}^{0}=10.14$ & - & $q_{2}^{\mathrm{sb}}=9.78$ & - \\
\hline & Baseline & $t_{1}^{0}=18.81$ & - & $t_{2}^{\mathrm{sb}}=18.19$ & - \\
\hline & & $U_{1}^{0}=53.38$ & - & $U_{2}^{\mathrm{sb}}=52.17$ & - \\
\hline \multirow{3}{*}{$c=1.5$} & & $q_{1}^{0}=10.36$ & $+2.17 \%$ & $q_{2}^{0}=10.08$ & $+3.07 \%$ \\
\hline & $-25 \%$ & $t_{1}^{0}=13.98$ & $-25.68 \%$ & $t_{2}^{0}=13.62$ & $-25.12 \%$ \\
\hline & & $U_{1}^{0}=58.48$ & $+9.55 \%$ & $U_{2}^{0}=57.14$ & $+9.53 \%$ \\
\hline
\end{tabular}

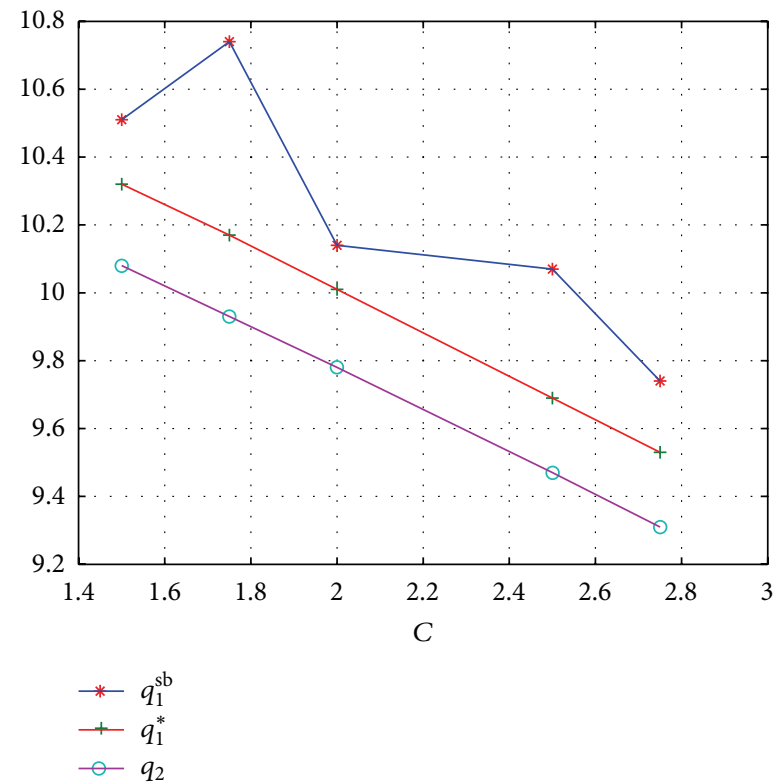

FIGURE 6: The order quantities change by the unit manufacturing cost.

for the low-risk retailer in full information contract $q_{1}^{*}$, and the order quantity for the high-risk retailer in full information contract which is equal to that in low-information-intensity allocation $q_{2}$. Both the order quantity for the low-risk retailer in full information and the order quantity for the high-risk retailer decrease by the unit manufacturing cost, and they change in the same level basically. But the change of the order quantity for the low-risk retailer in low information intensity depends on different values of the unit manufacturing cost. When the unit manufacturing cost $c=2.75$, the order quantity is minimum, and when $c=1.75$ or $c=1.5$, the order quantity is the maximum.

Figure 7 shows the sensitivity analyses for the transferring payment versus the unit manufacturing cost, in which the transferring payments include the transferring payment for the low-risk retailer in low-information-intensity allocation $t_{1}^{0}$, the transferring payment for the low-risk retailer in full information contract $t_{1}^{*}$, and the transferring payment for

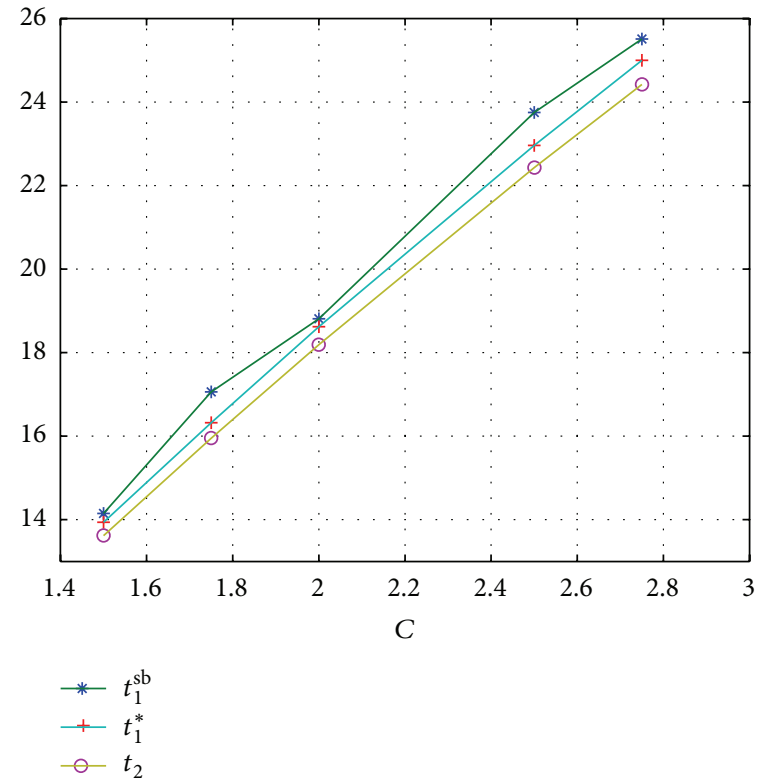

FIGURE 7: The transferring payments change by the unit manufacturing cost.

the high-risk retailer in full information contract which is equal to that in low-information-intensity allocation $t_{2}$. All the transferring payments of the retailers increase by the unit manufacturing cost. The transferring payments for the lowrisk retailer and the high-risk retailer in full information contract decrease in the same level.

Figure 8 shows the sensitivity analyses for the retailers' utilities versus the unit manufacturing cost, in which the utilities include the utility for the low-risk retailer in lowinformation-intensity allocation $U_{1}^{0}$, the transferring payment for the low-risk retailer in full information contract $U_{1}^{*}$, and the transferring payment for the high-risk retailer in full information contract which is equal to that in lowinformation-intensity allocation $U_{2}$. All the retailers' utilities decrease by the unit manufacturing cost.

Figure 9 shows the sensitivity analyses for the low-risk retailer's signaling cost versus the unit manufacturing cost. 


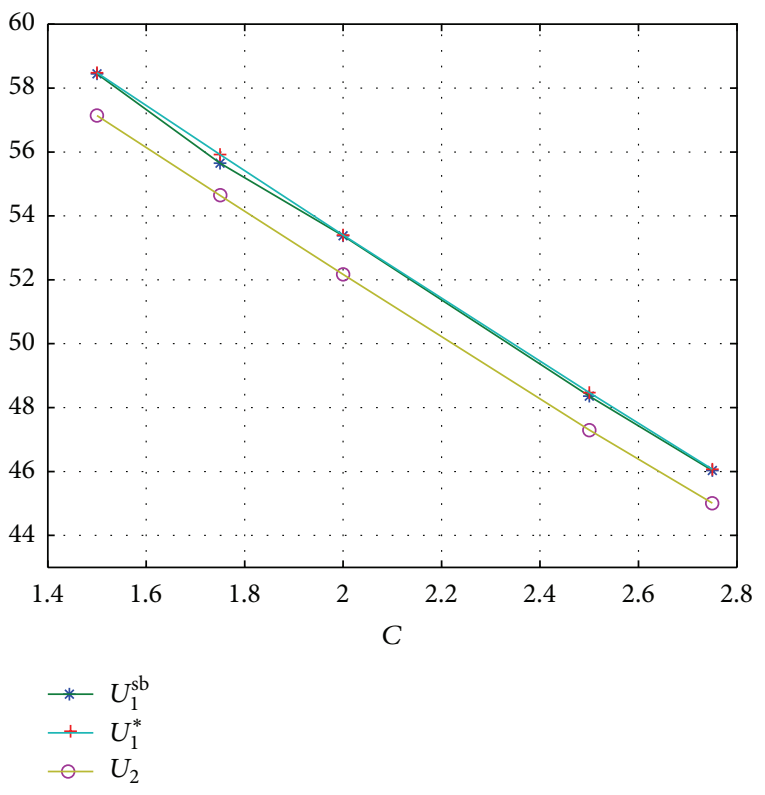

FIGURE 8: The retailer's utilities change by the unit manufacturing cost.

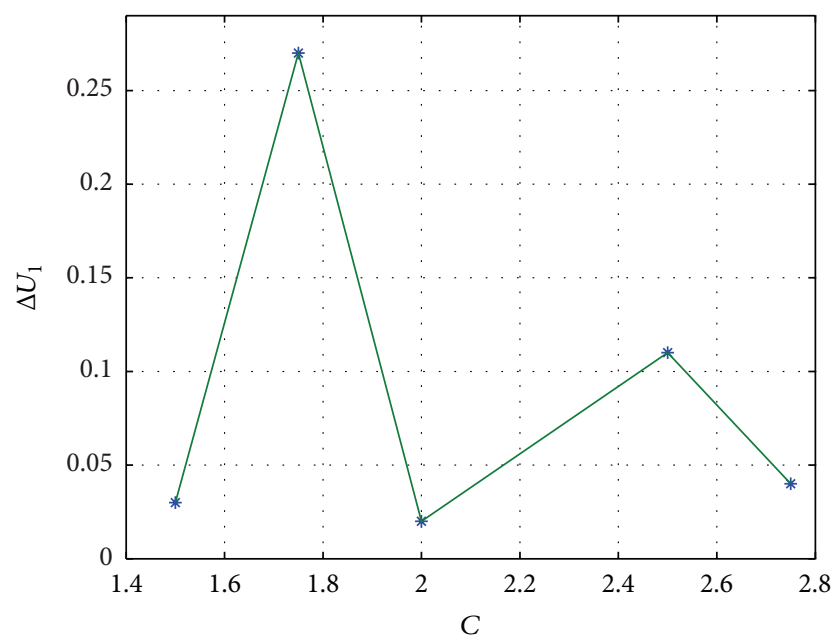

FIGURE 9: The signaling cost changes by the saved unit manufacturing cost.

The signaling cost of the low-risk retailer is the utility earned in the low-information-intensity allocation, which is separating contract, less than that in full information contract. When the unit manufacturing cost $c=2$, the signaling cost is the least, while when the saved unit manufacturing cost $c=1.75$, the signaling cost is the most. We do not find the internal relationship between the signaling cost and the unit manufacturing cost. As the signaling cost is so important to put the contracts into practice, investigation on the signaling cost is the research direction for us.

\section{Conclusion}

In the recent years, supply chain with demand disruption has become more and more attractive to both business and academic research. There is a lot of research available on the topic of supply chain disruption contract. In the real supply chain practice, demand disruption is totally different from the stochastic demand. So in our research, both the demand uncertainty and the demand disruption are considered. Taking the demand disruption probability as the asymmetric information, an informed principal model is explored to make the contract for supply chain with demand disruption. And the conclusions we obtain are shown as follows:

(1) The contracts for low-risk retailer and high-risk retailer in full information are provided, and it is found out that the high-risk retailer has the incentive to pretend to be the low-risk retailer. This result is similar to the other informed principal model [34, 35 ] but totally different from the normal principal agent model $[24,26]$. In the normal principal agent model, the high efficient agent (low-risk retailer in our setting) tries to pretend to be low efficient agent (highrisk retailer) to get more. That is why the informed principal model is established.

(2) The low-information-intensity allocation which is the result of the informed principal model and also is the separating contract shows that the order quantity and the transferring payment for the low-risk retailer in low-information-intensity allocation distort upwards, but that of high-risk retailer does not distort. In order to avoid imitation, the imitators' efficiency should be always distorted. But in normal principal agent model, the high-risk retailer's quantity distorts downwards $[24,26]$; on the contrary the low-risk retailer's quantity in informed principal model distorts upwards.

(3) In order to reduce the signaling cost which the lowrisk retailer pays, the interim efficient model is introduced, which ends up with the order quantity and transferring payment distorted upward again but less than that of low information intensity. Comparing to [38], focusing on analyzing the signaling cost, more attention is paid to showing the interim efficient model to get a solution which can increase efficiency.

From the managerial aspect, retailers should try to increase their antirisk capability to enhance competitive power. And when the retailer has lower demand disruption probability than the others, it can show its style to the supplier through the separating contract. For example, the retailer can say "because I am the low-risk one, I can cooperate with the supplier with this contract, while the others who are high-risk ones can only use the other contract." But in order to be separated from the others, the low-risk retailer has to pay some signaling cost, and the quantity has to be distorted upwards.

Above all, there are some limitations of the research. We will continue our research in the following directions. (1) The signaling cost is a key factor impacting the separating contract, which should be paid more attention. (2) We only consider the demand disruption, but disruptions happen at not only demand side but also supply side. So we will continue 
our research with demand disruption together with supply disruption [39].

\section{Appendix}

\section{A. Proof of Proposition 6}

For the two types of retailers, we can obtain the optimal allocation if and only if the whole margin utility of the supply chain is the same with the margin cost. So $q_{1}^{*}$ and $q_{2}^{*}$ satisfy the following first-order conditions:

$$
\begin{aligned}
& p S^{\prime}\left(\alpha_{1}, q_{1}\right)+s I^{\prime}\left(\alpha_{1}, q_{1}\right)=c \\
& p S^{\prime}\left(\alpha_{2}, q_{2}\right)+s I^{\prime}\left(\alpha_{2}, q_{2}\right)=c .
\end{aligned}
$$

And the optimal transferring payments are

$$
\begin{aligned}
& t_{1}^{*}=c q_{1}^{*}-s I\left(\alpha_{1}, q_{1}^{*}\right), \\
& t_{2}^{*}=c q_{2}^{*}-s I\left(\alpha_{2}, q_{2}^{*}\right) .
\end{aligned}
$$

From (A.1) and (A.2), we obtain

$$
\begin{aligned}
\theta_{1} G\left(q_{1}^{*}\right)+\left(1-\theta_{1}\right) F\left(q_{1}^{*}\right) \\
\quad=\theta_{2} G\left(q_{2}^{*}\right)+\left(1-\theta_{2}\right) F\left(q_{2}^{*}\right)=\frac{(p-c)}{(p-s)} .
\end{aligned}
$$

In addition, $G\left(q_{1}^{*}\right) \geq F\left(q_{1}^{*}\right), \alpha_{1}<\alpha_{2}$, so we know that $\alpha_{1} G\left(q_{1}^{*}\right)+\left(1-\alpha_{1}\right) F\left(q_{1}^{*}\right)<\alpha_{2} G\left(q_{1}^{*}\right)+\left(1-\alpha_{2}\right) F\left(q_{1}^{*}\right)$, and from (A.4), we obtain $\alpha_{2} G\left(q_{2}^{*}\right)+\left(1-\alpha_{2}\right) F\left(q_{2}^{*}\right)<\alpha_{2} G\left(q_{1}^{*}\right)+(1-$ $\left.\alpha_{2}\right) F\left(q_{1}^{*}\right)$, and thus $q_{2}^{*}<q_{1}^{*}$. From (A.3), $t_{1}^{*}-t_{2}^{*}=c\left(q_{1}^{*}-q_{2}^{*}\right)-$ $s\left(I\left(\alpha_{1}, q_{1}^{*}\right)-I\left(\alpha_{2}, q_{2}^{*}\right)\right), t_{1}^{*}-t_{2}^{*} \underset{q_{1}^{*}=q_{2}^{*}}{=}\left(\alpha_{1}-\alpha_{2}\right) s\left(\int_{0}^{q} F(y) d y-\right.$ $\left.\int_{0}^{q} G(x) d x\right)>0$, and $\partial t_{1}^{*} / \partial q_{1}^{*}>0$, so $t_{1}^{*}-t_{2}^{*}>0$, and thus we obtain $t_{1}^{*}>t_{2}^{*}, V_{1}^{*}=V_{2}^{*}=0$. Furthermore, we get $U_{1}^{*}>U_{2}^{*}$ from $\partial U / \partial \theta<0$ and $\partial U / \partial q>0$. Finally, we have Proposition 6.

\section{B. Proof of Proposition 12}

We denote $\mu_{1}$ and $\mu_{2}$ as the Lagrange multipliers of (6) and (14) and find the derivate of $t_{1}$ and $q_{1}$, and thus we obtain

$$
\begin{aligned}
\frac{\partial U\left(\alpha_{1}, q_{1}\right)}{\partial t_{1}}= & -1+\mu_{1}+\mu_{2}=0 \\
\frac{\partial U\left(\alpha_{1}, q_{1}\right)}{\partial q_{1}}= & p S^{\prime}\left(\alpha_{1}, q_{1}\right)-\mu_{1} c+\mu_{1} s I^{\prime}\left(\alpha_{1}, q_{1}\right) \\
& -\mu_{2} p S^{\prime}\left(\alpha_{2}, q_{1}\right)=0 .
\end{aligned}
$$

By rewriting (B.1) we get the following formulas:

$$
\begin{aligned}
& s I^{\prime}\left(\alpha_{1}, q_{1}^{s}\right)+p S^{\prime}\left(\alpha_{1}, q_{1}^{s}\right)-c \\
& =\frac{\left(1-\mu_{1}\right)}{\mu_{1}}\left[p S^{\prime}\left(\alpha_{2}, q_{1}^{s}\right)-p S^{\prime}\left(\alpha_{1}, q_{1}^{s}\right)\right], \\
& \mu_{1}=\frac{p S^{\prime}\left(\alpha_{2}, q_{1}^{s}\right)-p S^{\prime}\left(\alpha_{1}, q_{1}^{s}\right)}{s I^{\prime}\left(\alpha_{1}, q_{1}^{s}\right)+p S^{\prime}\left(\alpha_{2}, q_{1}^{s}\right)-c} \\
& \mu_{2}=\frac{s I^{\prime}\left(\alpha_{1}, q_{1}^{s}\right)+p S^{\prime}\left(\alpha_{1}, q_{1}^{s}\right)-c}{s I^{\prime}\left(\alpha_{1}, q_{1}^{s}\right)+p S^{\prime}\left(\alpha_{2}, q_{1}^{s}\right)-c} .
\end{aligned}
$$

Because the numerator of $\mu_{1}$ is negative, so $\mu_{1}$ is positive and the denominator of $\mu_{1}$ is negative; because $\mu_{2}$ is positive (when $\mu_{2}=0$, it cannot be separated from the former one), the numerator of $\mu_{2}$ is negative; nevertheless, $p S^{\prime}\left(\alpha_{1}, q_{1}^{*}\right)-$ $c+s I^{\prime}\left(\alpha_{1}, q_{1}^{*}\right)=0$, and thus $p S^{\prime}\left(\alpha_{1}, q_{1}^{s}\right)-c+s I^{\prime}\left(\alpha_{1}, q_{1}^{s}\right)<$ $p S^{\prime}\left(\alpha_{1}, q_{1}^{*}\right)-c+s I^{\prime}\left(\alpha_{1}, q_{1}^{*}\right)$; in addition, $\partial^{2} U / \partial q^{2}<0$, so $q_{1}^{s}>$ $q_{1}^{*}$. From $\mu_{1}>0$ and $\mu_{2}>0$, we deduce that (6) and (14) are tight. Furthermore, the programs $\left\{P_{F}^{1}\right\}$ and $\left\{P_{m}^{1}\right\}$ have the same objective function, but the constraint of $\left\{P_{m}^{1}\right\}$ is more tight, so there is distortion of the utility obtained from $\left\{P_{m}^{1}\right\}$; in other words, $U_{1}\left(t_{1}^{s}, q_{1}^{s}\right)<U_{1}^{*}$. From Proposition 11, we obtain $U_{2}\left(t_{2}^{0}, q_{2}^{0}\right)=U_{2}^{*}$. So we have Proposition 12 .

\section{Proof of Propositions 14 and 15}

We denote $\beta$ and $\gamma$ as the Lagrange multipliers of (19) and (20) and find the derivate of $t_{1}, q_{1}$, and $\widehat{R}$, and thus we obtain

$$
\begin{aligned}
\frac{\partial L\left(t_{1}, q_{1}, \widehat{R}\right)}{\partial t_{1}}= & -1+\beta \lambda+\gamma=0, \\
\frac{\partial L\left(t_{1}, q_{1}, \widehat{R}\right)}{\partial q_{1}}= & p S^{\prime}\left(\alpha_{1}, q_{1}\right)+\beta \lambda\left[-c+s I^{\prime}\left(\alpha_{1}, q_{1}\right)\right] \\
& -\gamma p S^{\prime}\left(\alpha_{1}, q_{1}\right)=0, \\
\frac{\partial L\left(t_{1}, q_{1}, \widehat{R}\right)}{\partial \widehat{R}}= & -\beta(1-\lambda)+\gamma=0 .
\end{aligned}
$$

To solve (C.1)-(C.3), we obtain $\beta=1, \gamma=1-\lambda$. And considering (C.2), we get

$$
\begin{aligned}
& s I^{\prime}\left(\alpha_{1}, q_{1}^{m}\right)+p S^{\prime}\left(\alpha_{1}, q_{1}^{m}\right)-c \\
& \quad=\frac{1-\lambda}{\lambda}\left[p S^{\prime}\left(\alpha_{2}, q_{1}^{m}\right)-p S^{\prime}\left(\alpha_{1}, q_{1}^{m}\right)\right] .
\end{aligned}
$$

Because (19) and (20) are tight, we obtain the following results:

$$
\begin{aligned}
t_{1}^{m} & =(1-\lambda) \\
& \cdot\left[p S\left(\alpha_{2}, q_{1}^{m}\right)-p S\left(\alpha_{2}, q_{2}^{*}\right)+c q_{2}^{*}-s I\left(\alpha_{2}, q_{2}^{*}\right)\right] \\
& +\lambda\left[c q_{1}^{m}-s I\left(\alpha_{1}, q_{1}^{m}\right)\right] \\
t_{2}^{m} & =(1-\lambda)\left[c q_{2}^{*}-s I\left(\alpha_{2}, q_{2}^{*}\right)\right]+\lambda p S\left(\alpha_{2}, q_{2}^{*}\right) \\
& +\lambda\left[c q_{1}^{m}-s I\left(\alpha_{1}, q_{1}^{m}\right)-p S\left(\alpha_{2}, q_{1}^{m}\right)\right] .
\end{aligned}
$$


To compare (A.1) with (C.4), we know $q_{1}^{m}>q_{1}^{*}$ because $\partial^{2} U / \partial q^{2}<0$ and $p S^{\prime}\left(\alpha_{2}, q\right)-p S^{\prime}\left(\alpha_{1}, q\right)<0$, and the distortion level is changing with $\alpha$. Finally we have Proposition 14.

To compare (C.4) with (B.2) and designate $\lambda^{0}=\lambda=$ $\left(p S^{\prime}\left(\alpha_{2}, q_{1}^{0}\right)-p S^{\prime}\left(\alpha_{1}, q_{1}^{0}\right)\right) /\left(s I^{\prime}\left(\alpha_{1}, q_{1}^{0}\right)+p S^{\prime}\left(\alpha_{2}, q_{1}^{0}\right)-c\right)$, we have the following conclusions:

(1) When $\lambda=\lambda^{0}, q_{1}^{m}=q_{1}^{s}=q_{1}^{0}$, we obtain the same contracts with the low-information-intensity situation.

(2) When $\lambda<\lambda^{0}, q_{1}^{m}<q_{1}^{s}=q_{1}^{0}$, we know there is more distortion than the low-information-intensity allocation and it improves anything.

(3) When $\lambda>\lambda^{0}, q_{1}^{m}<q_{1}^{s}=q_{1}^{0}$, the interim efficient allocation can improve the low-information-intensity allocation. So we have Proposition 15.

\section{Variables/Notations}

$c: \quad$ Unit manufacturing cost

$\alpha_{1}: \quad$ Disruption probability of low-risk retailer

$y$ : $\quad$ Market demand without disruption

$F(\cdot)$ : Distribution function of demand without

disruption

$s: \quad$ Unit salvage value

A: $\quad$ Market scale without disruption

$S\left(\alpha_{i}, q_{i}\right):$ Expected sales

$I\left(\alpha_{i}, q_{i}\right)$ : Expected unsold quantity

$U_{i}: \quad$ Utility of the retailer

$\lambda: \quad$ Probability of low-risk retailer

$\alpha_{2}: \quad$ Disruption probability of high-risk retailer

$x: \quad$ Market demand with disruption

$G(\cdot)$ Distribution function of demand with

disruption

p: $\quad$ Retail price

$D: \quad$ Market scale with disruption

$V_{i}$ : $\quad$ Utility of the manufacturer.

Control Variables

$q_{i}$ : Order quantity

$t_{i}$ : Transferring payment.

\section{Competing Interests}

The authors declare that there is no conflict of interests regarding the publication of this paper.

\section{Acknowledgments}

This research was supported in part by a project supported by the Humanities and Social Sciences Project of the Education Ministry (no. 14YJC630187), Hebei Social Sciences Project (no. HB15GL058), and the Fundamental Research Funds for the Central Universities (no. 2016MS123).

\section{References}

[1] J. Barnett, F. Begen, S. Howes et al., "Consumers' confidence, reflections and response strategies following the horsemeat incident," Food Control, vol. 59, pp. 721-730, 2016.

[2] A. J. Schmitt and L. V. Snyder, "Infinite-horizon models for inventory control under yield uncertainty and disruptions," Computers \& Operations Research, vol. 39, no. 4, pp. 850-862, 2012.

[3] L. V. Snyder, Z. Atan, P. Peng et al., "OR/MS models for supply chain disruptions: a review," IIE Transactions, vol. 48, no. 2, pp. 89-109, 2016.

[4] X. Qi, J. F. Bard, and G. Yu, "Supply chain coordination with demand disruptions," Omega, vol. 32, no. 4, pp. 301-312, 2004.

[5] T. Xiao, G. Yu, Z. Sheng, and Y. Xia, "Coordination of a supply chain with one-manufacturer and two-retailers under demand promotion and disruption management decisions," Annals of Operations Research, vol. 135, pp. 87-109, 2005.

[6] F. Hu, C.-C. Lim, Z. Lu, and X. Sun, "Coordination in a singleretailer two-supplier supply chain under random demand and random supply with disruption," Discrete Dynamics in Nature and Society, vol. 2013, Article ID 484062, 12 pages, 2013.

[7] J. Li, X. Liu, J. Wu, and F. Yang, "Coordination of supply chain with a dominant retailer under demand disruptions," Mathematical Problems in Engineering, vol. 2014, Article ID 854681, 10 pages, 2014.

[8] K. Chen and T. Xiao, "Demand disruption and coordination of the supply chain with a dominant retailer," European Journal of Operational Research, vol. 197, no. 1, pp. 225-234, 2009.

[9] J. Li and F. T. S. Chan, "The impact of collaborative transportation management on demand disruption of manufacturing supply chains," International Journal of Production Research, vol. 50, no. 19, pp. 5635-5650, 2012.

[10] Y. Zheng, T. Shu, S. Wang, S. Chen, K. K. Lai, and L. Gan, "Demand disruption and coordination of supply chain via effort and revenue sharing," Applied Economics, vol. 47, no. 54, pp. 5886-5901, 2015.

[11] Q. Pang, Y. Hou, and Y. Lv, "Coordinating three-level supply chain under disruptions using revenue-sharing contract with effort dependent demand," Mathematical Problems in Engineering, vol. 2016, Article ID 9167864, 10 pages, 2016.

[12] M. Gümüş, S. Ray, and H. Gurnani, "Supply-side story: risks, guarantees, competition, and information asymmetry," Management Science, vol. 58, no. 9, pp. 1694-1714, 2012.

[13] K. B. Hendricks and V. R. Singhal, "An empirical analysis of the effect of supply chain disruptions on long-run stock price performance and equity risk of the firm," Production \& Operations Management, vol. 14, no. 1, pp. 35-52, 2005.

[14] W. Schimidt and A. Raman, "When supply-chain disruptions matter," Harvard Business School Working Paper 13-006, 2012.

[15] N. Bunkley, Piecing together a supply chain. The New York Times. 2013, http://www.nytimes.com/2011/05/13/business/ global/13auto.html?_r=0.

[16] S. Sarkar and S. Kumar, "A behavioral experiment on inventory management with supply chain disruption," International Journal of Production Economics, vol. 169, pp. 169-178, 2015.

[17] G. P. Cachon, "Supply chain coordination with contracts," Handbooks in Operations Research \& Management Science, vol. 11, pp. 227-339, 2003.

[18] C. J. Corbett and X. De Groote, “A supplier's optimal quantity discount policy under asymmetric information," Management Science, vol. 46, no. 3, pp. 444-450, 2000. 
[19] C. J. Corbett, "Stochastic inventory systems in a supply chain with asymmetric information: cycle stocks, safety stocks, and consignment stock," Operations Research, vol. 49, no. 4, pp. 487$500,2001$.

[20] A. Matopoulos, M. Vlachopoulou, V. Manthou, and B. Manos, "A conceptual framework for supply chain collaboration: empirical evidence from the agri-food industry," Supply Chain Management, vol. 12, no. 3, pp. 177-186, 2007.

[21] A. Y. Ha and S. Tong, "Contracting and information sharing under supply chain competition," Management Science, vol. 54, no. 4, pp. 701-715, 2008.

[22] Y.-W. Zhou, "A comparison of different quantity discount pricing policies in a two-echelon channel with stochastic and asymmetric demand information," European Journal of Operational Research, vol. 181, no. 2, pp. 686-703, 2007.

[23] X. Gan, S. P. Sethi, and J. Zhou, "Commitment-penalty contracts in drop-shipping supply chains with asymmetric demand information," European Journal of Operational Research, vol. 204, no. 3, pp. 449-462, 2010.

[24] D. Lei, J. Li, and Z. Liu, "Supply chain contracts under demand and cost disruptions with asymmetric information," International Journal of Production Economics, vol. 139, no. 1, pp. 116126, 2012.

[25] Z. B. Yang, G. Aydın, V. Babich, and D. R. Beil, "Supply disruptions, asymmetric information, and a backup production option," Management Science, vol. 55, no. 2, pp. 192-209, 2009.

[26] S. Huang and C. Yang, "Supply chain revelation mechanism design under asymmetric demand disruption information," Operations Research and Management Science, vol. 23, no. 6, pp. 116-127, 2014.

[27] S. Oh and Ö. Özer, "Mechanism design for capacity planning under dynamic evolutions of asymmetric demand forecasts," Management Science, vol. 59, no. 4, pp. 987-1007, 2013.

[28] Q. Feng, G. Lai, and L. X. Lu, "Dynamic bargaining in a supply chain with asymmetric demand information," Management Science, vol. 61, no. 2, pp. 301-315, 2015.

[29] Q. Li, B. Li, P. Chen, and P. Hou, "Dual-channel supply chain decisions under asymmetric information with a risk-averse retailer," Annals of Operations Research, 2015.

[30] J. Wei, K. Govindan, Y. Li, and J. Zhao, "Pricing and collecting decisions in a closed-loop supply chain with symmetric and asymmetric information," Computers and Operations Research, vol. 54, pp. 257-265, 2015.

[31] K. Inderfurth, A. Sadrieh, and G. Voigt, "The impact of information sharing on supply chain performance under asymmetric information," Production \& Operations Management, vol. 22, no. 2, pp. 410-425, 2013.

[32] R. B. Myerson, "Mechanism design by an informed principal," Econometrica, vol. 51, no. 6, pp. 1767-1797, 1983.

[33] E. Maskin and J. Tirole, "The principal-agent relationship with an informed principal: the case of private values," Econometrica, vol. 58, no. 2, pp. 379-409, 1990.

[34] E. Maskin and J. Tirole, "The principal-agent relationship with an informed principal, II: common values," Econometrica, vol. 60, no. 1, pp. 1-42, 1992.

[35] T. Mylovanov and T. Tröger, "Informed-principal problems in environments with generalized private values," Theoretical Economics, vol. 7, no. 3, pp. 465-488, 2012.

[36] T. Mylovanov and T. Tröger, "Mechanism design by an informed principal: private values with transferable utility," Review of Economic Studies, vol. 81, no. 4, pp. 1668-1707, 2014.
[37] C. Wagner, T. Mylovanov, and T. Tröger, "Informed-principal problem with moral hazard, risk neutrality, and no limited liability," Journal of Economic Theory, vol. 159, pp. 280-289, 2015.

[38] S. Galperti, "Common agency with informed principals: menus and signals," Journal of Economic Theory, vol. 157, pp. 648-667, 2015.

[39] H. Zhang, Y. Liu, and J. Huang, "Supply chain coordination contracts under double sided disruptions simultaneously," Mathematical Problems in Engineering, vol. 2015, Article ID 812043, 9 pages, 2015. 


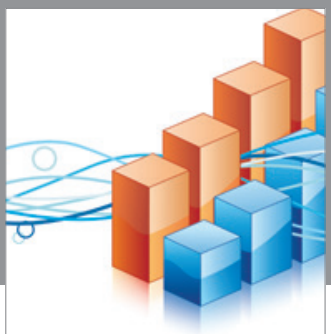

Advances in

Operations Research

vatem alat4

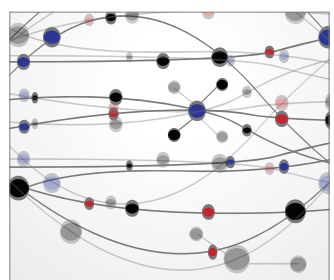

\section{The Scientific} World Journal
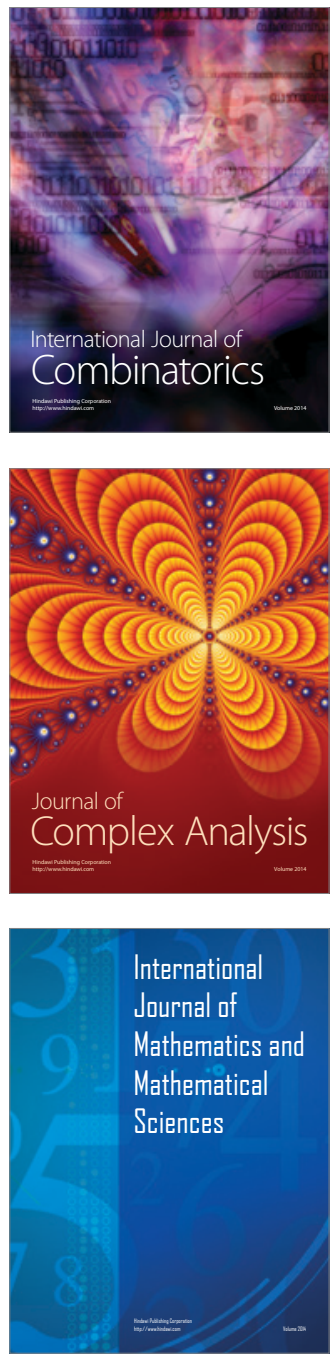
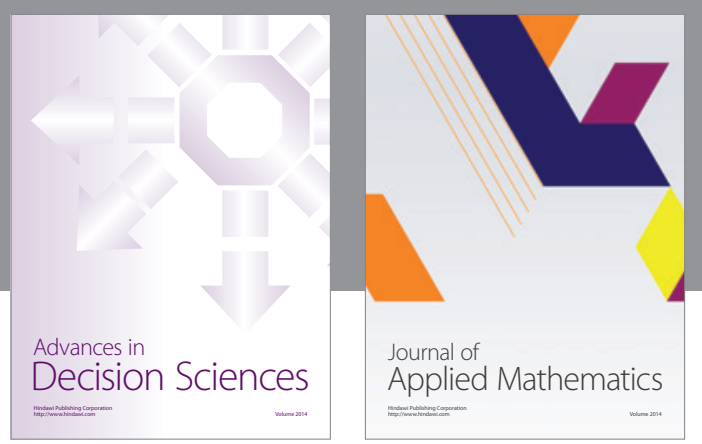

Algebra

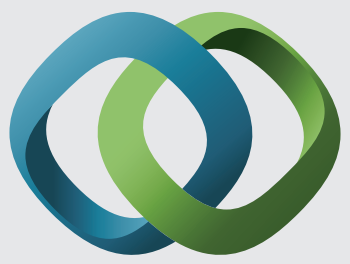

\section{Hindawi}

Submit your manuscripts at

http://www.hindawi.com
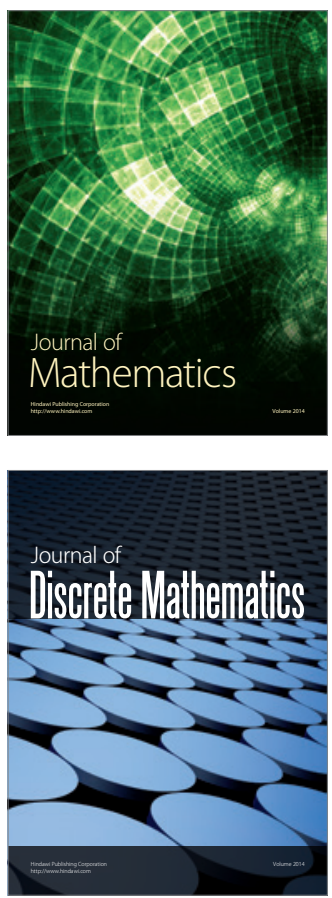

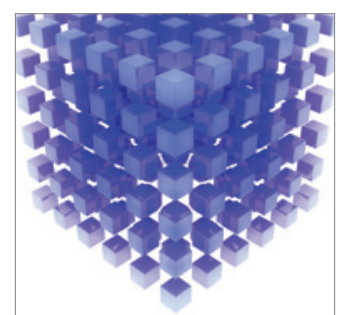

Mathematical Problems in Engineering
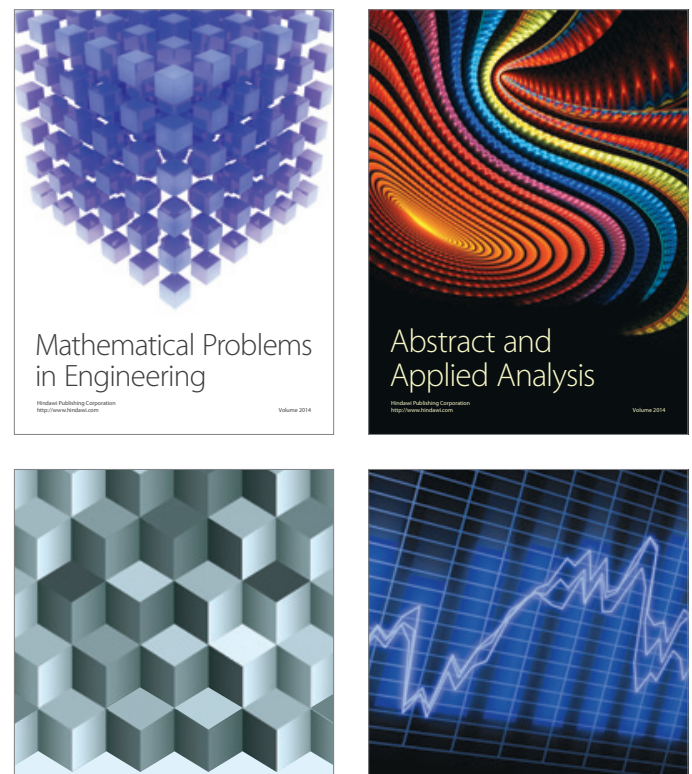

Journal of

Function Spaces

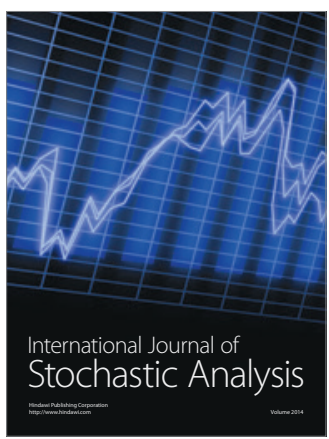

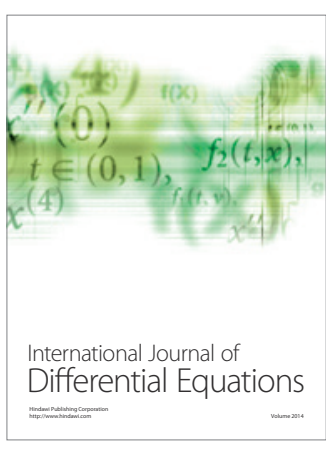
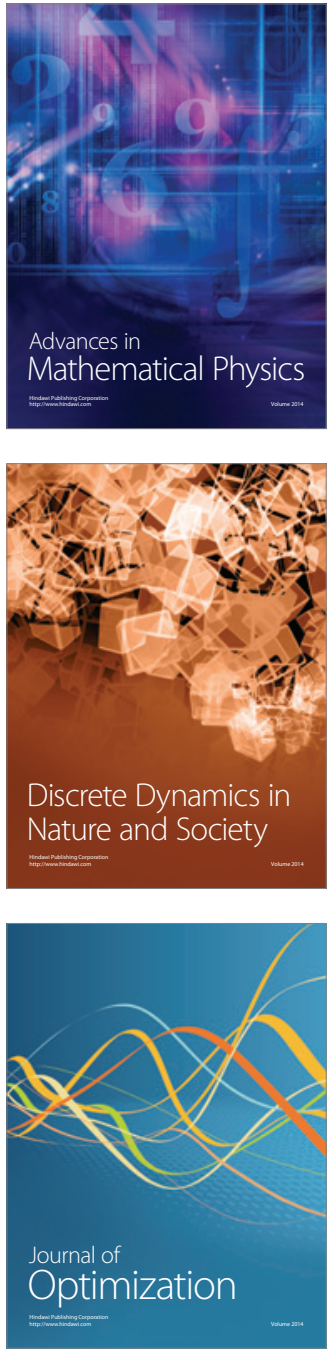